\title{
Precision crop production and artificial intelligence - the future of sustainable agriculture
}

MIKLÓS NEMÉNYI

Széchenyi István University, Faculty of Agricultural and Food Sciences, Department of Biosystems and Food Engineering, Mosonmagyaróvár, Hungary nemenyi.miklos@sze.hu

"It's difficult to make predictions, especially about the future" according to an old Danish proverb. At the same time: The best way to predict future is to create it (QuotesIdeas.com). The basic question is: How can we influence the future at the beginning of a paradigm shift?

\section{Summary - the basic question}

According to Kay et al. (2004, in Shockley et al., 2017), there are seven steps to the decision-making process: 1) Identify the problem or opportunity, 2) Identify the alternative solution, 3) Collect all data and information, 4) Analyse the alternatives and make a decision, 5) Implement the decision, 6) Monitor the results of the decision, 7) Accept responsibility for the decision. The basic question is what kind of tasks we can perform in the decision-making process and what to leave for Artificial Intelligence (AI).

Keywords: $2^{\text {nd }}$ machine age, green revolution, greening the green revolution, plant physiology models, big data, artificial intelligence, machine learning, deep learning, paradigm shift in education

\section{Introduction}

We stand before drastic changes. These changes will affect all areas of society: education, including advisory services and tutoring, logistics, decision-making, industrial and agricultural activities, transport, military defense technologies, households, services, urban living, relationships with our neighbors, relationships with our environment, relationships with ourselves; increasing lifespan, which also means that we need to work longer. Hospital care is changing, too, robots are now more accurate than the most skilled surgeon, and we need to learn new multimedia applications almost every day. Of course, the form of spending time on leisure will also change. This is just a taste of the many changes. We hear more and more about the unmanned factories, in addition, under the leadership of Prof. Simon Blackmore (Harper Adams University, UK), there is an experimental unmanned crop production 
system. I would add that the basic elements of an almost unmanned plant-growing technology are at our faculty, too.

The new era is symbolised by the "2nd machine age" the second industrial revolution (Brynjolfsson and McAffe, 2014). The first machine age contributed to the realisation of the Olympic Games' basic principles in industrial societies: Faster, Higher, Stronger (Citius, Altius, Fortius). By utilising the potential of the first machine age, we have been superseding our physical work. In the $2^{\text {nd }}$ machine age artificial intelligence replaces our intellectual work. Until today, man and the modern machine worked in symbiosis. From now on, the machine starts to live independently. This new situation raises new social problems both in developing and developed countries. In the developed countries, an increasing number of people are losing their jobs. The proportion of new jobs will be much less compared to this. Most of today's teenagers will work in a workplace that does not exist today, and we do not even know its name. It should be emphasised that this is not just about the low skilled worker: this change also affects the highly skilled workforce. There is, however, another aspect of the future in developed countries. Albert Szent-Györgyi, the Hungarian-American Nobel laureate professor said in a radio interview in 1973: "Our civilization is new and has not yet put our stamp on our bodies. If we want to be healthy, we must put our body back into the environment for which it has developed."

According to Friedman (2006) the driving force of $21^{\text {st }}$ century-society will not be multinational companies, but individual innovative skills. Questions: How can we make the development of individual innovative skills more effective? How can we influence the future? If we start from this fact, if we accept this prediction, in fact, the changes that seem to be unfavourable - today can have a positive impact on social development. In society there will be a large number of educated unemployed people at different levels who will be able to solve innovative tasks. I believe that innovative thinking and activity cannot be realised, in the near future, without the use of artificial intelligence.

\section{The direction and goal of innovation}

I would like to emphasise that digital systems, rapidly developing sensor techniques, remote sensing on different platforms, proximal sensory technique, sensor and data fusion, artificial intelligence, including machine learning and deep learning, and in particular unmanned or quasi unmanned production systems, are not the goal, but rather the tool for maintenance of dynamic ecological sustainability.

We know many general definitions of sustainability. I'm convinced that ecological reservation - nature and environment protection must be 
a priority in the nearest feature. All other aspects can only be considered after the fulfillment of the criteria for ecological sustainability, e.g. profitability etc. The main issue is to keep the balance between the two antagonistic players: agro- and natural ecology or landscape.

The sustainability criteria in agriculture will be constantly getting stricter. It can be summarized as follows: Fossil neutral production technologies, including biogas based $\mathrm{N}$ fertiliser production (Horváth et al., 2018); Nutrient replacement without nitrification and eutrophication of groundwater and surface water; Reducing the emission of nitrogen compounds from the soil; Production without soil erosion, salinization, acidification and harmful compaction; To avoid environmental pollution of chemicals: mainly pesticides.

An additional expectation is the maintenance of the diversity gradient to utilize the fertility potential. One of the most important advantages of digital agriculture is enabling the increase in production intensity so that sustainability is maintained (Kempenaar et al., 2016; Lindström and Lindblom, 2016; Urso et al., 2017). Consequently, intensification of agriculture and the exploitation of soil fertility can be solved together in a sustainable way. This is a very important statement, because there is an increasing demand for biological raw materials, not just for food stock, but also for bioplastics and so on. Earlier, intensification and sustainability were apposite concepts.

Energy balance also plays a determining role in the evaluation of plant production. The more human knowledge is in the plant production technology, the better the energy balance, the more environmentally friendly the technology (Neményi, 1983; Jordan, 2016; Neményi, 2017)

At the same time, it is very important to meet the criteria of food safety and quality as well. To this can also contribute the "soil to fork", or "farm to fork" complex technologies, these are closely related to precision agriculture. Sudduth, K.S. (2016, USDA-Agricultural Research Service Columbia, Missouri, USA) highlighted this in his lecture at the PREGA conference in Budapest.

\section{Green Revolution}

The father of the first Green Revolution was Norman Borlaug. He worked as a microbiologist in Mexico until 1944, and then started to work for the Rockefeller Foundation as a research assistant. The aim of the program was to increase wheat production in the developing countries.

But what is the Green Revolution? It was the first successful "system thinking" used in agriculture.

The system, which was the beginning of a new paradigm in crop production, integrated the operations and the materials used to achieve the highest yield: modern varieties, soil cultivation technology, advanced 
fertilizers, up to date weed control with advanced chemicals: state-of-theart irrigation systems with, of course, the latest state-of-the-art machinery.

Borlaug was a honorary member of the Hungarian Academy of Sciences, receiving Peace Nobel Prize in 1970.

\section{The greening of the green revolution}

David Tilman (1998) professor of ecology (University of Minnesota) made the following statement in Nature in his "The greening of the green revolution" study.

"Further advances, such as precision agriculture, in which fertilizer application rates and timing are adjusted differentially across a field to meet crop needs, will increase agricultural efficiency and decrease adverse effects on the environment. However, a greener revolution is also needed a revolution that incorporates accumulated knowledge of ecological processes and feedbacks, disease dynamics, soil processes and microbial ecology." Microbial ecology is the key point. 20 years have passed since the article appeared and effectively nothing has changed. There is little effort to know the biological processes in the soil. But without this, correct and accurate decision support models cannot be created. Actually, the end of the 1990s can be seen as the beginning of the Second Green Revolution.

\section{Crop production simulation models}

Plant physiology models try to consider a number of factors in order to clarify yield forecasts. They also contribute to increasing the efficiency of precise, site specific crop production. They provide assistance in planning agro-technology, analyzing expected impacts, preparing long-term strategic decisions, and creating cost-effective, economical forms of farming. Already in the 1970s, several models were developed (CERES: corn, wheat, millet, rice, SOYGRO: soybeans, SORGF: sorghum, TAMW: wheat, PNUTGRO: peanuts, BEANGRO: peas) to describe plant growth and development, forecasting the expected yield. Meanwhile, there is a clear need to create models for individual plants in a unified way, and that these models can receive climate models that are becoming more and more accurate during prediction. For this purpose, in 1982, the IBSNAT (International Benchmark Sites Network for Agrotechnology Transfer) started: NASA, Economic Research Service (ERS), Soil Conservation Service (SCS), Foreign Agriculture Service (FAS), National Oceanic Atmospheric Administration (NOAA), USDA and several US and foreign universities were launched. 
The best-known result of the project was the DSSAT (Decision Support System for Agrotechnology Transfer) software. The first version of DSSAT was realized in 1988; currently we use DSSAT v 4.6. In DSSAT more than 50 different types of data are required. In the case of soils this number is 20 to 22; weather data must be reported on a daily basis (Hoogenboom et al., 2003, 2010; Nyéki, et al. 2013; Nyéki, 2016). It follows from the foregoing statement that DSSAT and similar simulation models require a large number of accurate data (Nyéki et al., 2017).

The so-called VIS-NIR on-the-go multiple sensors, moved in the soil, can be used to measure many features at the same time, providing also the fusion of data. The method is elaborated by my former PhD student who is a professor at the University of Ghent (Mouazen et al., 2013). Very useful information is provided by the dielectric and magnetic properties of the soil (Nagy et al., 2013).

The platforms of remote sensing are satellite, aero plane, drone, this is UAV (Unmanned Aerial Vehicle), tractor with a console to analyze the surface of plant or soil. Using these possibilities, measurements can be carried out regularly during the vegetation period: they primarily contribute to controlling the yield prediction of the decision support models, can provide information for plant protection and so on. The most flexible tool is the drone.

\section{Precision agriculture}

In precision agriculture fields should be divided into a couple of hundreds of management zones, and the treatments are following this pattern. For the creation of management zones, fuzzy logic can be used (Mike-Hegedüs, 2006). It should be said that the smaller the manager zone, the closer we approach the above discussed model philosophy. We were among the first who used the DSSAT model in the different management zones (Neményi et al., 2003, 2006, 2008; Csiba, 2010; Csiba et al., 2013; Kovács et al., 2014). The time has come to deal with databases of a larger order of magnitude than traditional calculations and modeling methods are no longer suitable. The basic problems are as follows: practically the number of variables cannot be expanded; new variables can only be considered by software developers. At the same time, for the keeping of the balance between natural and agroecology, there should be much more information than before and the size of the management zones should be significantly reduced.

"Big Data" and the Artificial Intelligence

Nowadays, we capture as much data in two years as we have so far earlier. Database growth is exponential. This information background 
already satisfices the requirements of Artificial Intelligence (Sonka, 2014; Higgins et al., 2017; Shahar et al., 2017).

On one hand, data mining is also a new concept that seeks to recognize the aforementioned relationships. On the other hand, cloud computing will become the most typical. According to Michelangelo "the rock contains a statue, only the excess is to be cut out."

Large database have 3 basic features, 3V: Volume, Variety and High Speed Data Transmission (Velocity). The latter means that data is being transmitted in real time in and out of the system.

The number of variables is practically endless for AI-based models, and the relationship between dependent and independent variables is not required. The model will realize it. The period between 1945 and 2015 is somewhat arbitrary to the development of systemic technologies and the digitization of agriculture. In the new era, in the " $2^{\text {nd }}$ machine age" $\mathrm{AI}$ will play an increasingly important role.

Artificial Intelligence is currently the fastest growing area of computing. There are a number of definitions that can be summarized as follows: "AI is a type of computer technology which is concerned with making machines work in an intelligent way, similar to the way that the human mind works." (COBUILD Advanced English Dictionary).

Studying the articles in proceedings of ECPA (European Conference on Precision Agriculture)' 13, '15 and '17 one can conclude that the number of use Artificial Neural Network, machine learning, deep learning, robots using AI, data fusion etc. terms growths strongly. This is a data processing that cannot be programmed in the conventional way as described above.

With machine learning, mankind gets a new tool that can expand its knowledge and creativity. Basically, disease detection, weed classification, phenology typing etc. are used both for computer vision and machine vision coupled with machine learning (Moshou, 2013; Franco, 2015).

For example, machine learning can help in creating optimal learning processes. We can reach the end of tasks that we could not solve by other means. The time comes when the opinion of Hungarian-American and English scientist Michael Polanyi becomes overwhelming, namely "one knows more than he can express." AI helps to activate our knowledge. The next level is deep learning. Deep learning is a form of recognition that is the most commonly used method. Artificial vision-based pattern recognition is applied to weed control (Dyrmann et al., 2017); the separation of soil and weeds; identification of plant pathogens, the display of biotic and abiotic effects, and the selection of resistant genotypes can also be carried out by deep learning. Artificial Intelligence also helps in technical development: it is possible to check the precision 
of the parcel seed drill on-the-go evaluation with machine vision on cameras mounted on the spray boom. It can significantly reduce the amount of herbicide use.

Also, AI is used when robots and drones, as well as other devices are working in the fleet (Ribeiro at al., 2015). AI is also used when classifying on the basis of quality characteristics of product at the time of harvesting (Oppenheim and Shani, 2017), when identifying persons or animals moving in front of a machine during machine work like self-driving cars.

The number of articles dealing with sustainability is also growing. However, one cannot find any studies in the "precisian" literature trying to consider the two types of ecology (natural and agro-) as one unit. Although, the remote sensing systems and robots can collect information from the two systems at the same time. Using computational intelligence for the continuous analyses of such big data, the efficiency of sustainable plant production can be enhanced (Elgaali and Garcia, 2004).

"Agriculture, and especially precision agriculture, in my view, pushes the system to the right of the natural balance point." (Robert Ulanowicz (1943-), University of Florida, verbal communication)

\section{Yield prediction based on AI algorithms instead of plant physiology models}

One of the basic goals is to use phenology models based on AI. This is the start of the new paradigm in agriculture. Of course, I could not strive for completeness, but these areas are well illustrated by the widespread nature of the $\mathrm{AI}$ and how $\mathrm{AI}$ will appear in agricultural practice.

The study of Pantazi et al. (2016) can be considered as a milestone of AI application in yield forecasting. They used Counter-Propagation Artificial Neural Networks: CP-ANNs, XY-fused Networks: (XY-Fs) and Supervised Kohonen Networks: (SKNs) for yield prediction of wheat. The average overall accuracy for SKN was $81.65 \%$, for CP-ANN $78.3 \%$ and for XY-F $80.92 \%$, showing that the SKN model had the best overall performance. At the same time, they used three yields of frequency classes: low, medium and high yield. Prediction of SKN algorithm for low yield class showed $91 \%$. This can be considered as a highly accurate procedure.

This year we began to apply artificial intelligence in the case of our research. We cooperate with the Institute for Computer Science and Control of the Hungarian Academy of Science. To predict the yield of maize, we are using an XGBoost deep learning algorithm that is not a neural network-based model. However, this is an excellent tool for defining and prioritizing the limiting factors. In case of our results, the accuracies of yield prediction are similar to those mentioned above by 
examining a 9-year-long production period. From these studies, it can be concluded that the number of independent variables should be significantly increased so that accuracy can also be increased.

\section{A paradigm shift in education}

Important questions also concerning education are: What will be the farmer's job in the future? What kind of decisions can be made by farmers?

Here the 4Cs (critical thinking, communication, collaboration, creative thinking) capabilities can develop in project- or program-based learning. The number of capabilities can be supplemented.

Why involve students in the projects in the developed countries? The answer is evident. The young generation brings a new approach to solving problems. "The significant problems we face cannot be solved at the same level of thinking we were at when we created them." (Albert Einstein)

But at the same time, high-level education programs should also take into account the Carl Friedrich Gauss statements: "Science is the friend of practice, but not its slave. "Theory attracts practice as the magnet attracts iron.," The two statements are true together.

- Thesis 1: The education of the $21^{\text {st }}$ century should be oriented towards the project learning and at the same time to individuals. A group study also means that subtasks are selected according to the affinity of the students. Albert Einstein wrote, "Everybody is a genius. But if you judge a fish by its ability to climb a tree, it will live its whole life believing, that it is stupid."

- Thesis 2: Already in elementary school or even in kindergarten, it is necessary to start preparing the pupil for 4 Cs skills. By doing so, the difference between the teaching methods used in each age group decreases considerably.

- Thesis 3: Research, practice and education and advisory or extension programs are getting closer and closer together. We had previously taken the farm to school, now we have to take the school to the farm. On the other hand, the gap between basic and applied research is getting smaller.

- Thesis 4: We have to find a favorable ratio between virtual and practical education.

Universities will soon become virtual institutions in which professors are chosen from the whole world. We can interact with their lectures from anywhere in the world.

At the same time, the conditions creating unmanned crop production are getting more and more developed. How can we prepare for this challenge? Certainly farmers must be better involved in further training than ever before. 
The Australian-New Zealand initiative is very interesting: 7 universities have set up a Smart Farm Learning Hub Directly available on cloud-based technologies; students can get in touch with partners, get real-world data from the landscape, and develop critical thinking and problem solving skills. These are the most important issues (Trotter et al., 2016).

At the same time, it is very important to realise that, in addition to technical information technology, biological knowledge has to be deepened.

\section{Epilogue}

But this new situation also affects the events of the whole world. We trust, that we can find new ways of reducing hunger and deep poverty at various points in the world. At the same time, AI can help to mitigate the global and local consequences of climate change (Elgaali and Garcia, 2004).

In general, we can say that the transformation of technological paradigms is only followed by social transformation by phase delay. This has been true since the beginning of Industrial Revolution. The time period between the two paradigm shifts has shortened. It follows that the difference between the development of social structure and the expectation of the new conditions, caused by the rapid technological development, will be greater and greater.

One of the interesting changes in the second machine age is "As more and more artificial intelligence is entering into the world, more and more emotional intelligence must enter into leadership." Amit Ray, Mindfulness Meditation for Corporate Leadership and Management.

\section{Acknowledgments}

The work is supported by VKSZ_12-1-2013-0034 "Agricultural Climate" Competitiveness and Excellence Contract and EFOP 3.6.3.

\section{References}

Brynjolfsson, E.-McAffe, A. (2014): The second machine age. W.W. Norton \& Company.

Csiba, M. (2010): Development of measurement techniques for precision plant production. PhD Thesis. University of West-Hungary. Mosonmagyaróvár.

Csiba, M.-Kovács, A. J.-Virág, I.-Neményi, M. (2013): The most common errors of capacitance grain moisture sensors - effect of volume change during harvest. Precision Agric. 14: 215-223. 
Dyrmann, M.-Jørgensen, R. N.-Midtiby, H. S. (2017): RoboWeed Support Detection of weed locations in leaf occluded cereal cropsusing a fully convolutional neural network. ECPA. 842-847.

Elgaali, E.-Garcia, L. (2004): Neural Network Modeling of Climate Change Impacts on Irrigation Water Supplies in Arkansas River Basin. Hydrology Day. Colorado State University.

Franco, C. A. (2015): An image-based decision support methodology for weed management. ECPA. 591-601.

Friedman T. L. (2006): És mégis lapos a föld - A XXI. század rövid története. HVG Kiadó Rt. Budapest.

Higgins, S.-Schellberg J.-Bailey, J. S. (2017): A Review of Precision Agriculture as an aid to Nutrient Management in Intensive Grassland Areas in North West Europe. ECPA. 782-786.

Hoogenboom, G.-Jones, J. W.-Porter, C. H.-Wilkens, P. W.-Boote, K. J.-Hunt, L. A.Tsuji, G. Y. (2010): Decision Support System for Agrotechnology Transfer (DSSAT) Version 4.5 (CD-ROM), volume 1. Overview. University of Hawaii. Honolulu.

Hoogenboom, G.-Jones, J.-Porter, C. H.-Wilkens, P. W.-Boote, K. J.-Batchelor, W. D.Hunt, L. A.-Tsuji, G. Y. (2003): Decision Support System for Agrotechnology Transfer (DSSAT) Version 4.0, volume 1. Overview. University of Hawaii. Honolulu.

Horváth, T.-Nyéki, A.-Neményi, M. (2018): The energy balance of maize production. Acta Agraria Debreceniensis. 74: 59-63.

Jordan, C. F. (2016): The Farm as a Thermodynamic System: Implications of the Maximum Power Principle. Biophys. Econ. Resour. Qual. 1: 9.

Kempenaar, C. C.-Kocks, C. G.-Been, T.-Evert van, F. K.-Nysten, S. W. P.-Westerdijk, C. E. (2016): Towards data-intensive, more sustainable farming: advances in predicting crop growth and use of variable rate in prediction crop growth and use of variable rate technology in arable crops in the Netherland. $13^{\text {th }}$ International Conference on Precision Agriculture. July 31-August 4. St. Louis. USA.

Kovács, A. J.-Nyéki, A.-Milics, G.-Neményi, M. (2014): Climate change and sustainable precision crop production with regard to maize (Zea mays L.). 12 $2^{\text {th }}$ International Conference on Precision Agriculture.] Sacramento. USA. 1-14.

Lundström, C.-Lindblom, J. (2016): Considering Farmers' situated expertise in using AgriDSS to foster sustainable farming practices in precision agriculture. $13^{\text {th }}$ International Conference on Precision Agriculture. July 31-August 4. St. Louis. USA.

Mike-Hegedüs, F. (2006): Applying fuzzy logic and neural networks to database evaluation in precision agriculture. PhD Thesis. University of West-Hungary. Mosonmagyaróvár.

Moshou, D. (2013): Crop and weed species based on hyperspectral sensing and active learning. ECPA. 555-561.

Mouazen, A. M.-Alhwaimw, S. A.-Kuang, B.-Waine, T. W. (2013): Fusion of data from multiple soil sensors for the delineation of water holding capacity zones. ECPA. 745-751. 
Nagy, V.-Milics, G.-Smuk, N.-Kovács, A. J.-Balla, I.-Jolánkai, M.-Deákvári, J.-Szalay, K. D.-Fenyvesi, L.-Štekauerová, V.-Wilhelm, Z.-Rajkai, K.-Németh, T.-Neményi, M. (2013): Continuous field soil moisture content mapping by means of apparent electrical conductivity (ECa) measurement. J. Hydrol. Hydromech. 61. 4: 305-312.

Neményi, M. (1983): Improvement of energy balance of maize production, in particular the factors affecting the heat consumption of artificial drying of grain. PhD Thesis. Mosonmagyaróvár. Agricultural Faculty. Hungarian Academy of Sciences.

Neményi, M. (2017): Thoughts and questions about the sustainability of agriculture in the modern digital age: theoretical and practical approach. [In: Nyéki, A. et al. (eds.) Towards sustainable agricultural and biosystems engineering.]

Neményi, M.-Mesterházi, P. Á.-Milics, G. (2006): An Application of Tillage Force Mapping as a Cropping Management Tool. Biosyst. Eng. 94. 3: 351-357.

Neményi, M.-Mesterházi, P. Á.-Pecze, Zs.-Stépán, Zs. (2003): The role of GIS and GPS in precision farming. Computers and Electronics in Agriculture. 40. 1-3: 45-55.

Neményi, M.-Milics, G.-Mesterházi, P. Á. (2008): The role of the frequency of soil parameter database collection with special regard to online soil compaction measurement. [In: Formato, A. (ed.) Advances in Soil and Tillage Research.] 125-139.

Nyéki, A. (2016): Relationship between precision crop production and sustainable agriculture. PhD Thesis. Széchenyi István University. Mosonmagyaróvár.

Nyéki, A.-Milics, G.-Kovács, A. J.-Neményi, M. (2013): Improving yield advisory models for precision agriculture with special regards to soil compaction in maize production. ECPA. 443-448.

Nyéki, A.-Milics, G.-Kovács, A. J.-Neményi, M. (2017): Effects of soil compaction on cereal yield: review. Cereal Res. Commun. 45. 1: 1-22.

Oppenheim, D.-Shani, G. (2017): Potato Disease Classification Using Convolution Neural Networks. ECPA. 244-249.

Pantazi, X. E.-Moshou, D.-Alexandridis, T.-Whetton, R. L.-Mouazen, A. M. (2016): Wheat yield prediction using machine learning and advanced sensing. Computers and Electronics in Agriculture. 57-65, 121.

Ribeiro, A.-Fernandez-Quintanill, C.-Dorado, J.-Lopez-Granados, F.-Pena, J. M.Rabatel, G.-Perez-Ruiz, M.-Conesa-Mufi, J.-Gonzalez de Santos, P. (2015): A fleet of aerial and ground robots: a scalable approach for autonomous site-specific herbicide application. ECPA. 167-173.

Shahar, Y.-Blacker, C.-Kavanagh, R.-James P.-Taylor, J. A. (2017): Implementation of Ag Data Agricultural Services for Precision Agriculture. ECPA. 656-661.

Shockley, J.-Mark, T.-Dillon, C. (2017): Educating producers on the profitability of precision agriculture technologies. ECPA. 724-727.

Sonka, S. (2014): Big Data and the Ag Sector: More than Lots of Numbers. International Food and Agribusiness Management. Review. 17. 1: 19.

Sudduth, K. A. (2016): The right decisions should be made in the right place and time. [In: Erdei, G.-Milics, G. (eds.) Precision management, digitization before and over.] PREGA. 14. 
Tilman, D. (1998): The greening of the green revolution. Nature. 396: 211-212.

Trotter, M.-Gregory, S.-Trotter. T.-Acuna, T.-Swaina, S.-Fasso, W.-Roberts, J.-Zikan, A.-Cosby, A. (2016): SMARTfarm Learning Hub: Next Generation Precision Agriculture Technologies for Agricultural Education. 13 ${ }^{\text {th }}$ International Conference on Precision Agriculture. July 31-August 4. St. Louis. USA. 1-9.

Urso, L. M.-Wegener, J. K.-Hörsten von, D.-Minben, T. F.-Gaus, C. C. (2017): Crop Production of the future - possible with a new approach? ECPA. 734-737. 